\title{
Spatial and temporal differences in fecundity of Atlantic herring (Clupea harengus) off Nova Scotia and consequences for biological reference points
}

\author{
Timothy J. Barrett, Adrian R. Hordyk, Melanie A. Barrett, and Michael R. van den Heuvel
}

\begin{abstract}
The relationships between fecundity and size of Atlantic herring (Clupea harengus) were estimated within five different spawning areas off the coast of Nova Scotia in 2019 and 2020. Statistically significant differences in fecundity relative to body weight were observed among spawning areas and between years. Fecundity-at-length on the German Bank spawning ground was $29 \%-36 \%$ and $22 \%-28 \%$ lower than estimates from 2001 and 1970, respectively. Temporal changes in weightand relative fecundity-at-age resulted in a decrease in the number of eggs-per-recruit (in an equilibrium unfished state) by $50 \%$ and a decrease of $27 \%$ in the egg production per tonne of spawning stock biomass (SSB) in 2020 relative to 1970. Decreases in SSB-per-recruit and eggs-per-recruit over time resulted in proportional decreases in equilibrium SSB at maximum sustainable yield (MSY); however, the fishing mortality rate (F) at MSY remained relatively stable over time. Total egg production was shown to be disproportional to SSB. Equilibrium SSB at MSY was greater (and F at MSY lower) when estimated using eggs-per-recruit compared to SSB-per-recruit. Failing to account for fecundity and assuming that egg production is proportional to SSB resulted in an overestimate of stock status.
\end{abstract}

Résumé : Les relations entre la fécondité et la taille des harengs atlantiques (Clupea harengus) ont été estimées pour cinq lieux de frai différents au large de la Nouvelle-Écosse en 2019 et 2020. Des différences statistiquement significatives de la fécondité par rapport à la masse corporelle sont relevées entre les lieux de frai et d'une année à l'autre. La fécondité selon la longueur sur le banc German et de $29-36$ \% et 22-28 \% plus faible que les valeurs estimées pour 2001 et 1970, respectivement. Des changements dans le temps de la masse et de la fécondité relative selon l'âge se traduisent par une diminution du nombre d'œufs par recrue (dans un état d'équilibre sans pêche) de 50 \% et une baisse de $27 \%$ de la production d'œufs par tonne de biomasse du stock reproducteur (BSR) en 2020 par rapport à 1970. Des baisses de la BSR-par-recrue et des œufspar-recrue au fil de temps se traduisent par des diminutions proportionnelles de la BSR pour un rendement maximum durable (RMD); cependant, le taux de mortalité par pêche (F) au RMD demeure relativement stable au fil du temps. Il est démontré que la production d'œufs totale n'est pas proportionnelle à la BSR. La BSR à l'équilibre au RMD est plus grande (et F au RMD est plus faible) quand elle est estimée en utilisant les oufs-par-recrue plutôt que la BSR-par-recrue. Le fait de ne pas tenir compte de la fécondité et de présumer que la production d'œufs est proportionnelle à la BSR se traduit par une surestimation de l'état du stock. [Traduit par la Rédaction]

\section{Introduction}

Estimation of life history parameters is important for understanding fish population dynamics and estimating biological reference points (BRPs) used for management decisions (Brooks et al. 2010; Zhou et al. 2020). BRPs (e.g., the expected biomass or fishing mortality rate (F) corresponding with maximum sustainable yield (MSY) and the spawning potential ratio (SPR)) are used by fisheries managers to inform stock status and to make management decisions. The $F$ corresponding with MSY $\left(F_{M S Y}\right)$ represents the theoretical fishing pressure that maximizes yield over the long term, and SPR represents the ratio of the number of spawners (or eggs) produced over an average recruit's lifetime for a given $F$ to the number of spawners (or eggs) produced without fishing (Brooks et al. 2010; Mangel et al. 2013). One objective of BRPs is to avoid negative effects on productivity, with a focus on avoiding impacts on recruitment (e.g., Myers et al.1994; Shelton and Rice 2002; Nakatsuka et al. 2017). In many stock assessments, spawning stock biomass (SSB) is used as a proxy for the reproductive potential or total egg production (TEP) of a stock. The common assumption that reproductive potential is proportional to SSB (isometry) is, however, not met in many cases and is rarely evaluated (Hunter et al. 1985; Marshall et al. 1999; Rijnsdorp et al. 2010; Kell et al. 2016). A recent meta-analysis showed that assuming isometry overestimates the egg production of exploited fish stocks by $22 \%$ on average (Marshall et al. 2021). Older and more experienced females may contribute more to reproductive potential from higher fecundity, larger eggs, and increased survival of eggs and larvae relative to younger spawners (Trippel 1998; Murawski et al. 2001; Barneche et al. 2018). BRPs based on SSB may thus overestimate the resilience of a stock to fishing pressure at

Received 29 September 2021. Accepted 22 December 2021.

T.J. Barrett and M.A. Barrett. Fisheries and Oceans Canada, St. Andrews Biological Station, 125 Marine Science Dr., St. Andrews, NB E5B 2L9, Canada. A.R. Hordyk. Blue Matter Science Ltd., 2150 Bridgman Ave, North Vancouver, BC V7P 2T9, Canada.

M.R. van den Heuvel. Canadian Rivers Institute, Department of Biology, University of Prince Edward Island, 550 University Ave., Charlottetown, PE C1A 4P3, Canada.

Corresponding author: Timothy Barrett (email: Tim.Barrett@dfo-mpo.gc.ca).

() 2022 Author(s) Hordyk and van den Heuvel and the Crown. This work is licensed under a Creative Commons Attribution 4.0 International License (CC BY 4.0), which permits unrestricted use, distribution, and reproduction in any medium, provided the original author(s) and source are credited. 
Fig. 1. Map of mainland Nova Scotia showing sampling locations for 5 spawning areas in Northwest Atlantic Fisheries Organization areas 4VWX. Map created using ArcGIS with "ne_10m_coastline.shp” basemap from Kelso (2021) and a NAD83 CSRS projection. [Colour online.]

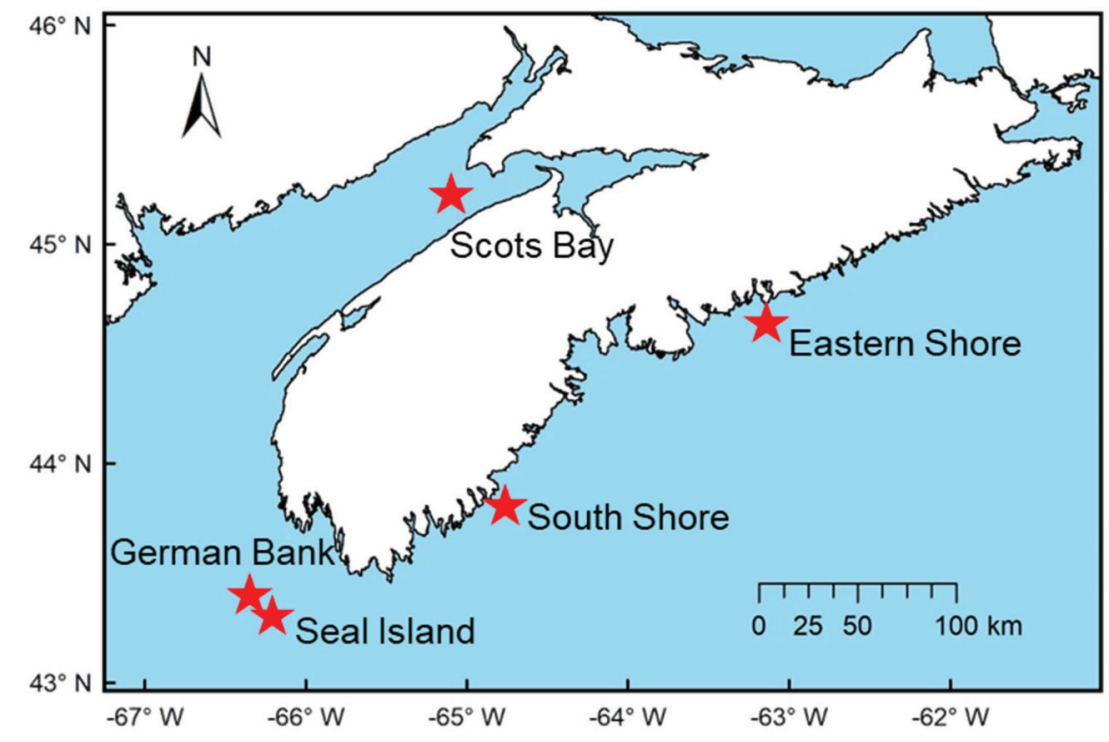

lower stock levels (Murawski et al. 2001), and using TEP instead of SSB to estimate BRPs may better reflect states at risk of serious harm and thus improve fisheries management outcomes.

The Atlantic herring (Clupea harengus) stock in Northwest Atlantic Fisheries Organization (NAFO) subdivisions 4VWX off Nova Scotia consists of five management units and several discrete spawning areas (DFO 2020). The 4VWX Atlantic herring stock consists of primarily fall spawners (Melvin et al. 2009; Wuenschel and Deroba 2019) and several reproductively isolated (spatialtemporal) subpopulations (Stephenson et al. 2009). Atlantic herring spawn once per year and are considered a total spawner (all eggs released within a single spawning event) and therefore have a determinate fecundity (Kurita and Kjesbu 2009). Variability in fecundity of Atlantic herring has been shown to be influenced by body size (van Damme et al. 2009), prior food conditions and spawning time (dos Santos Schmidt et al. 2017), and egg size (Bradford and Stephenson 1992; dos Santos Schmidt et al. 2021). Fecundity provides an estimate of TEP under the assumption that the standing stock of oocytes are observed just prior to spawning (Kjesbu 2009). Timing of estimating fecundity in Atlantic herring is important as many authors have reported down-regulation of fecundity by atresia in advance of spawning (e.g., Kurita et al. 2003; Óskarsson and Taggart 2006; van Damme et al. 2009). Size-specific fecundity has been observed to vary spatially and temporally (Rideout and Morgan 2007; van Damme et al. 2009), and consideration of this variation is necessary to ensure an accurate perception of stock reproductive potential (Rogers et al. 2019).

The objectives of this study were to (1) describe the fecundity of $4 \mathrm{VWX}$ Atlantic herring relative to weight, length, and age for different spawning grounds using linear regression, (2) assess temporal changes in fecundity-at-size of 4VWX Atlantic herring using historical data, (3) assess the assumption that TEP is proportion to SSB (i.e., reproductive isometry; Marshall et al. 2021) from the relationship between fecundity and mass for Atlantic herring, and (4) assess the influence of temporal changes in biological parameters on the estimation of BRPs and stock status of Atlantic herring based on SSB at MSY $\left(\mathrm{SSB}_{\mathrm{MSY}}\right)$ using an age-structured operating model from the latest modelling framework.

\section{Methods}

\section{Data collection}

A sample of 25-30 female Atlantic herring per sampling date were obtained from the commercial fishery during the spawning season in 2019 and 2020 in five spawning areas in NAFO subdivisions 4VWX (German Bank, Scots Bay, Seal Island, South Shore Nova Scotia, and Eastern Shore Nova Scotia; Fig. 1). All samples were collected between 12 August and 31 October in both years (Supplementary Table S1 ${ }^{1}$ ). Samples from German Bank, Scots Bay, and Seal Island were obtained opportunistically from the purse seine fishery, and samples from South Shore and Eastern Shore were obtained from the gill net fishery. Samples were kept on ice and processed within four hours after the fish were landed. Total length (nearest $0.1 \mathrm{~cm}$ ), body weight and ovary weight (nearest $0.01 \mathrm{~g}$ ), and the macroscopic maturity stage used by Fisheries and Oceans Canada (DFO) for their biological sampling program (Supplementary Table S2 ${ }^{1}$; Landry and McQuinn 1988) were recorded. A sample of the ovary (approximately $2 \mathrm{~g}$ ) was cut and stored in a vial of $10 \%$ buffered formalin for estimation of fecundity. Sagittal otolith pairs were removed from the fish sampled in 2019, rinsed with water, and placed in acrylic trays with well plates. The otoliths were then prepared for aging by embedding in the well plates using Cytoseal 60, a low viscosity mounting solution.

Estimates of fecundity were obtained for fish with macroscopic maturity stages of 4 or 5 (ripening II or ripe; Supplementary Table S2 ${ }^{1}$ ), consistent with the spawning capable phase of development (Brown Peterson et al. 2011) with a single developing cohort of oocytes estimated to be between the late vitellogenic and the hydration stages. Fecundity was estimated using the gravimetric method. A subsample of approximately $0.1 \mathrm{~g}$ (on average 175 oocytes) was taken from the preserved ovary sample, blotted dry, and weighed to the nearest $0.001 \mathrm{~g}$. The developing cohort of oocytes were of a similar size and counted under a Zeiss Stemi 200 -CS binocular microscope at $8 \times$ magnification. The fecundity of each fish was estimated as the product of the oocyte counts in the subsample and the ratio of the whole ovary weight to the ovary subsample weight from which the oocytes were counted. Fecundity estimates were made in triplicate for every tenth

${ }^{1}$ Supplementary data are available with the article at https://doi.org/10.1139/cjfas-2021-0269. 
sample and the mean coefficient of variation among triplicate samples was $3.4 \%$, which was considered acceptable precision (Óskarsson et al. 2002; Óskarsson and Taggart 2006). The subsample of ovary preserved for fecundity estimates was blotted dry and weighed again prior to estimating fecundity to evaluate changes in weight due to preservation in formalin for approximately $10 \%$ of samples (Óskarsson et al. 2016). A significant difference was detected using a paired $t$ test $(p<0.001, n=81)$, and the mean subsample weight after preservation was on average $4.0 \%$ greater than the pre-preserved subsample weight. Final fecundity estimates were therefore multiplied by 1.04 to account for the change in weight.

Age was estimated from the otoliths by technicians in the Atlantic herring group at DFO's St. Andrews Biological Station. The group estimates ages of more than 3000 Atlantic herring per year as part of annual assessments of Atlantic herring in Southwest Nova Scotia - Bay of Fundy. Quality control measures include comparisons to an otolith reference collection to provide a standard for intra-reader comparisons, as well as annual self-testing for the primary ager on a random selection from the reference collection. Further details on the aging methods can be found in Melvin et al. (2010) and Singh et al. (2020).

\section{Data analysis}

\section{Fecundity by area}

Relationships between fecundity and fish size (total body weight and total length) were evaluated separately by area using analysis of covariance (ANCOVA) with year as a factor. The following model was fit:

$$
\begin{aligned}
\log _{10}(\text { Fecundity })=b_{0}+ & b_{1} \log _{10}(\text { Cov })+b_{2} \text { YR } \\
& +b_{3} \log _{10}(\text { Cov }) \times \mathrm{YR}+\epsilon
\end{aligned}
$$

where Fecundity is in thousands of oocytes, Cov is the covariate (body weight in $\mathrm{g}$ or total length in $\mathrm{cm}$ ), YR is an indicator variable for year ( 0 for 2019 and 1 for 2020), $b_{i}$ are the regression coefficients, and $\epsilon$ is the error term. A $\log _{10}$-transformation was selected based on better properties of the residual plots and a greater coefficient of determination $\left(R^{2}\right)$ relative to models with untransformed variables. When the covariate or year interaction term was not significant, it was dropped from the model. Subsequently, when the year term was not significant, it was also removed from the model. Ages were only estimated in 2019 and the relationship between fecundity and age was evaluated using simple linear regression for year 2019 only with no data transformation for fecundity or age. Observations with Studentized residuals of magnitude of 4 or more were removed from the statistical analyses as outliers (a single observation was removed from each regression for German Bank).

The magnitude of the slope of the relationship between $\log _{10}$ (Fecundity) and $\log _{10}$ (Body weight) was used to assess whether TEP is proportional to SSB (i.e., isometry; Marshall et al. 2021). A 95\% confidence interval was estimated for the slope (reproductive scaling coefficient in Marshall et al. 2021) using a margin of error defined as 1.96 times the standard error of the slope estimate.

\section{Spatial comparisons}

Spatial comparisons of relative fecundity were conducted among areas and years using ANCOVA with body weight as a covariate, since it had the highest $R^{2}$ among the potential covariates for fish size. The models were fit with $\log _{10}$ (Fecundity) as the response variable, $\log _{10}$ (Body weight) as the covariate, and factors year and area. A full model with all interaction terms was fit. When the three-way interaction term (Area $\times \mathrm{YR} \times$ Body weight) was not significant, it was dropped from the model. Subsequently, the two-way interaction terms were dropped from the model when they were not significant. Differences among areas were evaluated using least squares means (controlling for year effects) using Tukey's method for adjusting the significance level $(\alpha)$ for multiple comparisons. Multiple comparisons were conducted using the "emmeans" package in R (Lenth et al. 2021). All statistical comparisons were conducted using $\alpha=0.05$ and the magnitude of difference between areas was estimated at the mean value of the covariate. Observations with Studentized residuals of magnitude of 4 or more were removed from the statistical analyses as outliers (a single observation from German Bank in 2019).

\section{Temporal comparisons}

Temporal comparisons in fecundity-at-length were conducted for German Bank and the South Shore spawning areas using historical data. Fecundity-at-length relationships were available for German Bank from 2001 (Óskarsson et al. 2016) and 1970 (Messieh 1976). A fecundity-at-length relationship for South Shore was available from 1963 (Perkins and Anthony 1969). Variance estimates for the historical relationships were not available to conduct an ANCOVA, so comparisons (relative percent differences) in the predicted mean fecundity were conducted at different lengths (the minimum and maximum values of the overlap in length ranges among years).

\section{Influence of fecundity on reproductive potential and BRPs}

Calculations for BRPs were conducted for the Southwest Nova Scotia - Bay of Fundy (SWNS-BoF) Atlantic herring management component of the $4 \mathrm{VWX}$ stock using a single operating model from the ongoing management strategy evaluation for the stock (DFO, unpublished data). The operating model is an age-structured model with three fleets (1: purse seine with logistic selectivity, 2: gill net with dome-shaped selectivity, and 3: all other gears with dome-shaped selectivity) that assumes a Beverton-Holt stock recruitment relationship with an assumed initial steepness of 0.85 (selected based on maximum likelihood profiles) and a natural mortality rate of 0.35 . Biological data were available from 1970-2018 and were used to define 5-year time periods for evaluating changes in biological parameters on BRPs (1970: 1970-1974, 2000: 1998-2002, and 2020: 2014-2018). Fecundity-at-age was estimated using mean length- or weight-at-age and the relative fecundity relationships for German Bank from 1970 (Messieh 1976), 2001 (Óskarsson et al. 2016) and 2020 (German Bank fecundity-atweight relationship for 2020 from this study). The eggs-per-recruit

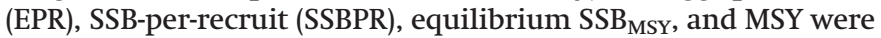
calculated for each 5-year time period (labelled as 1970, 2000, and 2020) to assess the influence of changes in biological parameters on BRPs using the average at-age estimates of body weight, maturity, and model-estimated selectivity (mean probability of being captured by the fleets) over the 5-year period (Supplementary Table S3 ${ }^{1}$ ).

The BRP calculations were conducted using $\mathrm{R}$ ( $\mathrm{R}$ Core team 2020) following the methods of Walters and Martel (2004). The approach uses the survivorship-at-age $\left(l_{a}\right)$ along with at-age estimates of weight $\left(w_{a}\right)$, fecundity $\left(f_{a}\right)$, selectivity $\left(v_{a}\right)$, natural mortality $\left(M_{a}\right)$, and maturity $\left(m_{a}\right)$ to calculate equilibrium metrics. The following were estimated:

$$
\begin{aligned}
& \text { equilibrium survivorship-at-age: } \\
& l_{a}= \begin{cases}1, & a=1 \\
l_{a-1} \mathrm{e}^{\left(-M_{a-1}-F v_{a-1}\right)}, & a>1, a<a_{\max } \\
\frac{l_{a-1} \mathrm{e}^{\left(-M_{a-1}-F v_{a-1}\right)}}{1-\mathrm{e}^{\left(-M_{a}-F v_{a}\right)},} & a=a_{\max }\end{cases}
\end{aligned}
$$

where $l_{a}$ is the survivorship-at-age $a, F$ is the instantaneous fishing mortality rate, and $a_{\max }$ is the maximum age of 11 (plus group) in the age structured model. 
Table 1. Regression coefficients and coefficient of determination $\left(R^{2}\right)$ for the analysis of covariance of $\log _{10}\left(\right.$ Fecundity) and $\log _{10}($ Body weight) and $\log _{10}$ (Length) with factor Year, separate by spawning area.

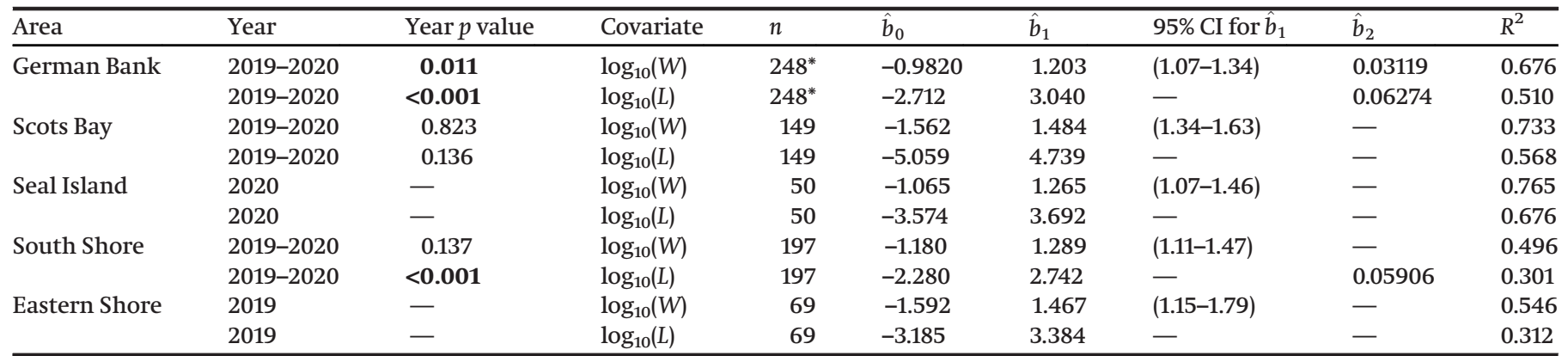

Notes: Coefficients for $\hat{b}_{2}$ are reported only when the term is significant and represents the additional intercept term for year 2020 . Units: Fecundity $=$ thousands of oocytes, body weight $(W)$ in $\mathrm{g}$, length $(L)$ in $\mathrm{cm}$. Bold $p$ values $<0.05$.

*One outlier removed from regression.

equilibrium eggs-per-recruit:

$\mathrm{EPR}=\sum_{a}\left(l_{a} f_{a} m_{a}\right)$

equilibrium SSB-per-recruit:

$$
\operatorname{SSBPR}=\sum_{a}\left(l_{a} w_{a} m_{a}\right)
$$

equilibrium yield-per-recruit:

$$
\mathrm{YPR}=\sum_{a}\left\{l_{a} w_{a} F v_{a}\left[1-\mathrm{e}^{\left(-M_{a}-F v_{a}\right)}\right] /\left(M_{a}+F v_{a}\right)\right\}
$$

The SPR was calculated in terms of TEP as $\mathrm{SPR}=\mathrm{EPR} / \mathrm{EPR}_{0}$, where $\mathrm{EPR}_{0}$ is the EPR in an unfished state $(\mathrm{F}=0)$. Relative recruitment at equilibrium under different $F$ was calculated assuming a BevertonHolt stock recruitment relationship as $R_{\mathrm{rel}}=(\alpha \mathrm{EPR}-1) / \beta \mathrm{EPR}$, where parameters $\alpha$ and $\beta$ are constant over time (Miller and Brooks 2021) and are defined as follows: $\alpha=\kappa \mathrm{EPR}_{0}$, where $\kappa$ is the compensation ratio, calculated from the assumed initial (over the first 5 historical years $=$ mean generation time for Atlantic herring) steepness $(h=0.85)$ of the stock recruitment relationship as $\kappa=4 h /(1-h)$ and $\beta=\left(\alpha \mathrm{EPR}_{0}-1\right) /\left(\mathrm{R}_{0} \mathrm{EPR}_{0}\right)$, where $R_{0}$ is the model-estimated initial unfished recruitment.

The SPR and relative recruitment for SSB were also calculated using SSBPR instead of EPR. Equilibrium yield was defined as YPR $\cdot R_{\text {rel }}$ and $F_{M S Y}$ was estimated as the $F$ that maximizes the equilibrium yield. The $\mathrm{SSB}_{\mathrm{MSY}}$ was calculated as the equilibrium SSB obtained from fishing at $F_{M S Y}$.

The influence of the change in fecundity-at-size over the three time periods on the reproductive dynamics of the stock was assessed by estimating the spawning stock numbers-at-age per tonne of SSB and the egg production-at-age per tonne of SSB. Fecundity was also expressed as relative fecundity (oocytes per $\mathrm{g}$ body weight) so the influence of changes in body weight on fecundity-at-age could be separated from changes in TEP for herring of the same age.

Stock status for the terminal historical year (2018) of the model was calculated as the ratio of the model estimated SSB in 2018 to $\mathrm{SSB}_{\mathrm{MSY}}$ using the different time periods that represent 5-year time blocks for selectivity and the biological parameters (1970, 2000, 2020).

\section{Results}

\section{Fecundity by area}

For each area and covariate combination, the interaction between year and covariate was not significant (i.e., the regression slopes were parallel between years) and the $b_{3}$ term was dropped from model 1. Significant differences between 2019 and 2020 fecundity relative to body weight and length were detected for German Bank (Table 1; Supplementary Fig. S1 ${ }^{1}$ ). The percent differences in fecundity-at-size in 2020 relative to 2019 at the mean body weight $(167 \mathrm{~g})$ and mean length $(15.5 \mathrm{~cm})$ were $7.4 \%$ and 16\%, respectively. A significant difference between 2019 and 2020 fecundity relative to length (but not body weight) was detected for South Shore (Table 1), and the percent difference in fecundity in 2020 relative to 2019 at the mean length $(28.4 \mathrm{~cm})$ was $15 \%$. No significant differences in fecundity-at-size were detected between years for Scots Bay (Table 1). Body weight was a better predictor of fecundity than length for each area (Table 1). Body weight and length were weaker predictors of fecundity for Eastern Shore and South Shore compared to German Bank, Scots Bay, and Seal Island. Age was a weaker predictor of fecundity compared to weight and length for German Bank $\left(R^{2}=0.220\right)$, Scots Bay $\left(R^{2}=0.520\right)$, and Eastern Shore $\left(R^{2}=0.103\right)$ and the regression for fecundity on age was not significant for South Shore (Supplementary Table S4, Fig. S2 ${ }^{1}$ ).

The slope of the $\log _{10}$ (Fecundity) vs. $\log _{10}$ (Body weight) linear relationships ranged from 1.20 to 1.48 among the five sampling areas (Table 1). The slopes for each area were significantly different from 1 ( $95 \%$ confidence intervals do not overlap 1$)$, implying egg production is not proportional to mass (Table 1 ).

\section{Spatial comparisons}

The three-way interaction term (Area $\times$ YR $\times$ Body weight) was not significant ( $p$ value $=0.079$ ) in the full model and this term was dropped from the model. The two-way interaction terms were also not significant ( $p$ values $\geq 0.150$ ) and were dropped from the model. The final model (with parallel regression slopes among areas and years) had a significant Area effect ( $p$ value $<0.001$ ) and a significant YR effect $(p$ value $=0.023$ ). Fecundity relative to body weight was significantly greater for Scots Bay relative to German Bank (6.5\%), South Shore (13\%), and Eastern Shore (11\%) (Fig. 2). Fecundity relative to body weight was significantly greater for Seal Island relative to South Shore (14\%) and Eastern Shore (12\%) and German Bank was significantly greater than South Shore (5.7\%) (Fig. 2). Fecundity relative to body weight was significantly greater in 2020 relative to 2019 (4.4\%).

\section{Temporal comparisons}

Comparisons of fecundity relative to length for German Bank were conducted at 27 and $32 \mathrm{~cm}$ (minimum and maximum overlapping lengths, respectively, among years; Fig. 3). Fecundity of a $27-\mathrm{cm}$ herring in $2019-2020$ was $29 \%$ and $22 \%$ lower relative to 2001 and 1970, respectively. Fecundity of a 32-cm herring in 2019-2020 was $36 \%$ and $28 \%$ lower relative to 2001 and 1970 , respectively. 
Fig. 2. Least squares means (black circles) and $95 \%$ confidence intervals (blue bars) for fecundity by area for a herring of mean body weight (173 g). Areas with red arrows that overlap are not significantly different (adjusted for multiple comparisons). Data labels are the back-transformed least squares means in thousands. Areas that share a letter (A, B, C, D) are not significantly different (family-wise $\alpha=$ 0.05). [Colour online.]

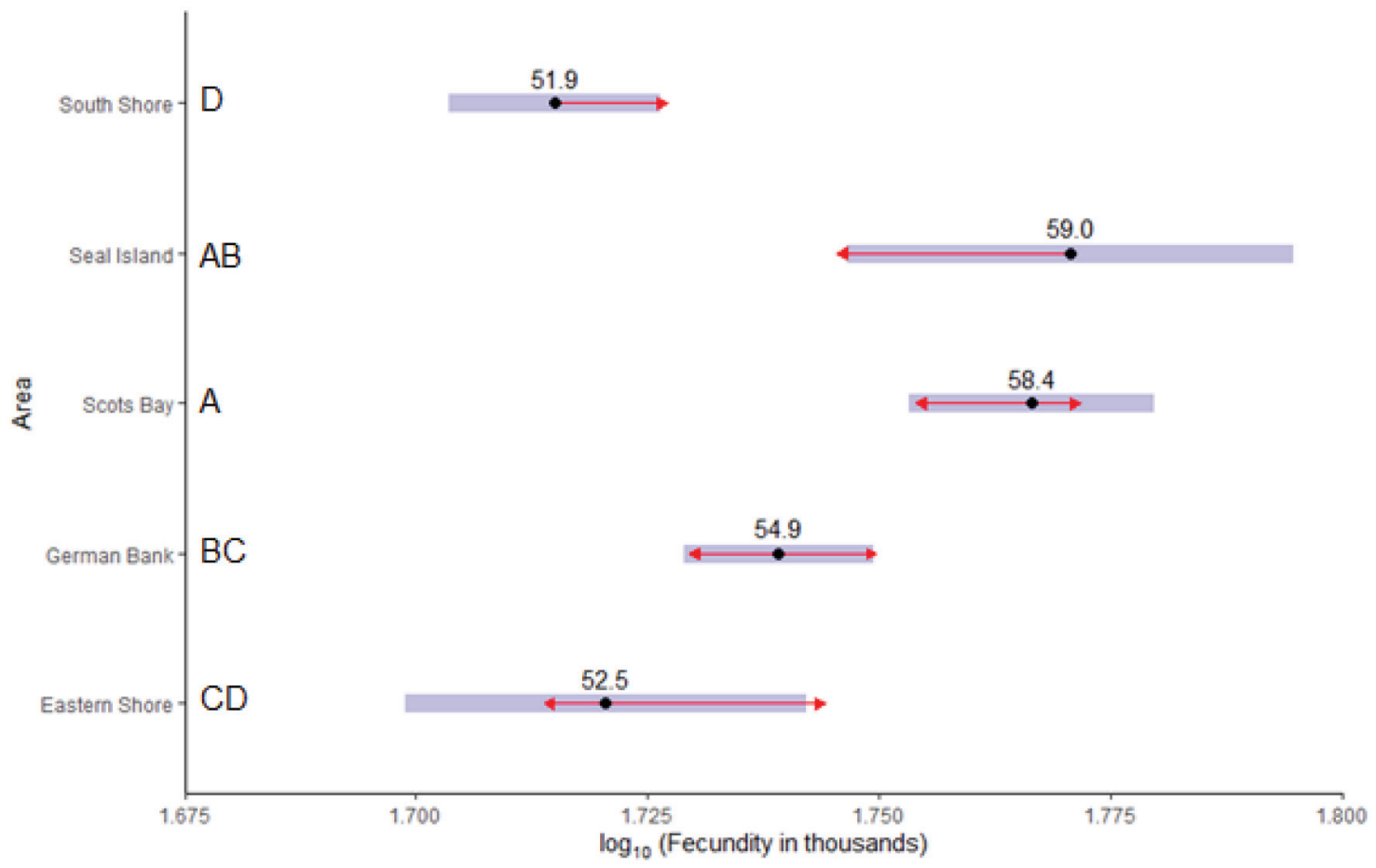

Fig. 3. Scatterplot (black observations) and linear regression (blue line and $95 \%$ confidence interval) of fecundity vs. total length for Atlantic herring collected on the German Bank spawning ground in 2019-2020. Red dashed line is linear regression for 1970 (Messieh 1976), and red dotted line is linear regression for 2001 (Óskarsson et al. 2016). Individual observations for 1970 and 2001 were not available. Regressions were fit on the $\log _{10}$-transformed variables for all years except 2001. [Colour online.]

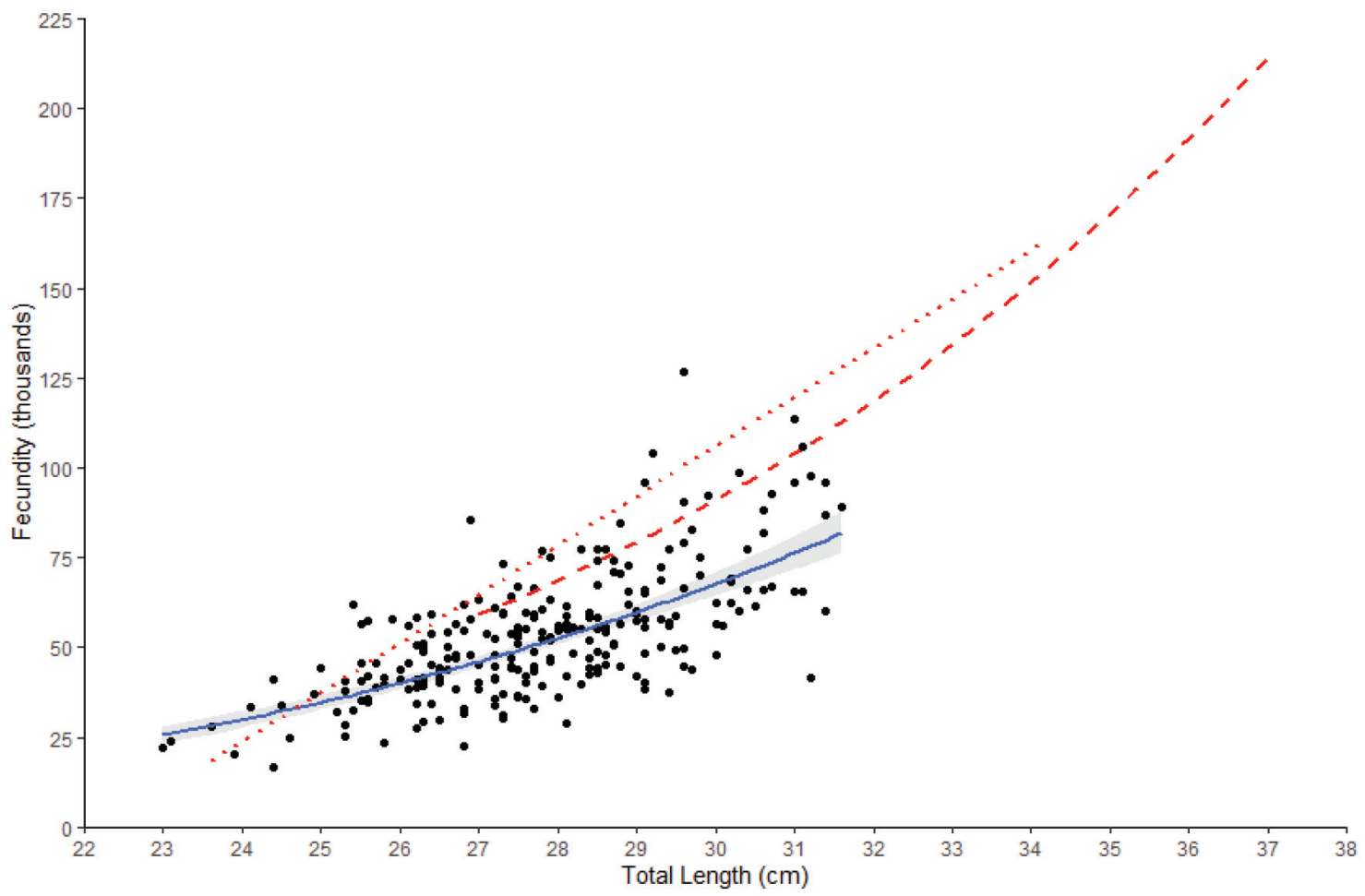


Fig. 4. Scatterplot (black observations) and linear regression (blue line and $95 \%$ confidence interval) of fecundity vs. total length for Atlantic herring collected on the South Shore spawning area in 2019-2020. Red dashed line is linear regression for 1963 (Perkins and Anthony 1969). Individual observations for 1963 were not available. Regression was fit on the $\log _{10}$-transformed variables in $2019-2020$. [Colour online.]

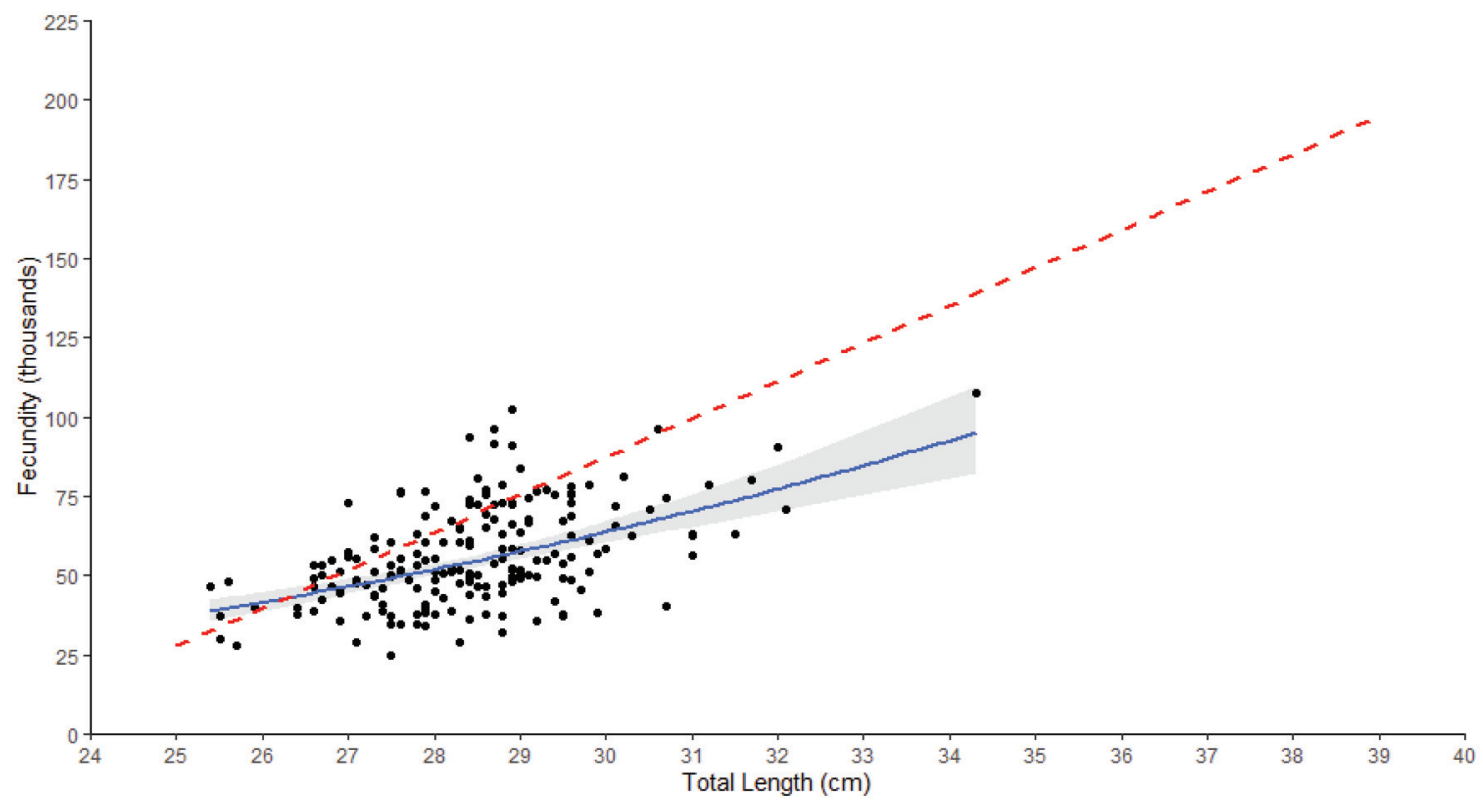

Comparisons of fecundity relative to length for South Shore were conducted at 26 and $34 \mathrm{~cm}$ (Fig. 4). The 95\% confidence interval for a $26-\mathrm{cm}$ herring in 2019-2020 overlapped with the regression line for 1963 , while the fecundity for a 32-cm herring was $32 \%$ lower relative to 1963 .

\section{Influence of fecundity on reproductive potential and BRPs}

The weight-at-age of the spawning stock (age 3+) has decreased over time (Fig. $5 a$ ) and combined with the changes in fecundity-atsize, contributes to the overall temporal change in fecundity-at-age (Fig. $5 d$ ). There has been almost no change in maturity-at-age over the three time periods (Fig. 5b) and little change in selectivity over time, with the exception of lower selectivity at age 2 in 1970 (Fig. 5c). The other parameters that influence the BRP calculations (i.e., natural mortality rate and stock recruitment parameters) were assumed constant over time in the model.

Fecundity-at-age decreased from 1970 to 2000 (Fig. 5d) but the relative fecundity (oocytes per g body weight) at-age was similar between the two time periods (Fig. 5e), suggesting the change in fecundity-at-age from 1970 to 2000 is due to changes in body weight (Fig. 6). Fecundity-at-age in 2020 , however, was $\geq 50 \%$ lower than the fecundity-at-age in $\mathbf{1 9 7 0}$ for ages $\mathbf{5 +}$ and this change was driven by decreases in both body weight and oocytes per g body weight (Figs. 5 and 6). Approximately $60 \%$ of the change in fecundity-at-age from 1970 to 2020 for ages 4+ (range of 58\%-64\% across ages) can be attributed to changes in body weight, and the remaining change $(\sim 40 \%)$ is due to changes in the oocytes per $g$ body weight (Fig. 6). For age 3, only $38 \%$ of the change in fecundityat-age from 1970 to 2020 can be attributed to changes in body weight (Fig. 6).

The at-age $\mathrm{EPR}_{0}$ decreased by $12 \%-24 \%$ for ages $4+$ from 1970 to 2000 and decreased by 41\%-59\% from 1970 to 2020 (Fig. 5f). The $\mathrm{EPR}_{0}$ for age 3 decreased $32 \%$ from 1970 to 2020 then increased to $12 \%$ below the $1970 \mathrm{EPR}_{0}$ in 2020 (Fig. $5 f$ ). The temporal changes in body weight and fecundity have resulted in changes in the structure of the spawning stock. The estimated number of fish per tonne of SSB increased over the time periods; 1970 (5416), 2000 (6077), and 2020 (7012), a 29\% increase from 1970 to 2020 (Fig. 5g). The egg production per tonne of SSB decreased 27\% from 1970 to
2020, dropping from 423 to 409 to 310 million eggs over the 1970 , 2000, and 2020 time periods, respectively (Fig. 5h).

The $29 \%$ decrease in $\mathrm{SSBPR}_{0}$ and $50 \%$ decrease in $\mathrm{EPR}_{0}$ from 1970 to 2020 resulted in a proportional decrease in the equilibrium $\mathrm{SSB}_{\mathrm{MSY}}$ by $29 \%$ (Table 2). There was little change in $\mathrm{F}_{\mathrm{MSY}}$ over time based on SSBPR (0.39 to 0.43 ) and a bit more variability in $F_{\text {MSY }}$ over time based on EPR (0.27 to 0.35 ; Table 2 ). The $F_{\text {MSY }}$ was lower $(0.08$ to 0.12$), \mathrm{SSB}_{\mathrm{MSY}}$ was greater $(22 \%-43 \%)$, and stock status was estimated to be lower (19\%-29\%) based on EPR compared to SSBPR (Table 2).

\section{Discussion}

The fecundity-at-size estimates described in this study are the first reported in almost two decades for Atlantic herring in NAFO subdivisions 4VWX. Although the Scots Bay, German Bank, and Seal Island spawning subpopulations are all part of the SWNS-BoF management component, significant differences in fecundity-at-size were detected between Scots Bay and German Bank. The Scots Bay spawning ground has an earlier spawning period (June-September) relative to German Bank and Seal Island (August-October; Singh et al. 2020). By convention, herring in the Northwest Atlantic that spawn January to June are considered spring spawners and herring that spawn July to December are considered fall spawners (Melvin et al. 2009). All herring sampled as part of the present study are therefore considered fall spawners.

There does not appear to be evidence that fecundity of Atlantic herring is influenced by the timing of spawning on the spawning grounds among fall spawners. Although spawning begins earlier in Scots Bay compared to German Bank and Seal Island, relative fecundity was not significantly different between Scots Bay and Seal Island, and the greater relative fecundity in Scots Bay compared to German Bank is not consistent with the differences between spring and fall spawning Atlantic herring observed between these two areas by Messieh (1976). In the early 1970s, Messieh (1976) found that fall spawners from SWNS (German Bank area) had significantly higher fecundity than spring (May) spawners from the Scots Bay area. Messieh (1976) also found that fall spawning Atlantic herring had higher fecundity than spring 
Fig. 5. Line plots by time period $(1970,2000,2020)$ showing at-age estimates of $(a)$ body weight, $(b)$ maturity, (c) selectivity, $(d)$ fecundity, (e) relative fecundity (oocytes per g body weight), $(f)$ unfished eggs-per-recruit $\left(\mathrm{EPR}_{0}\right),(g)$ number of fish per tonne of spawning stock biomass (SSB), and ( $h$ ) egg production (oocytes) per tonne of SSB.
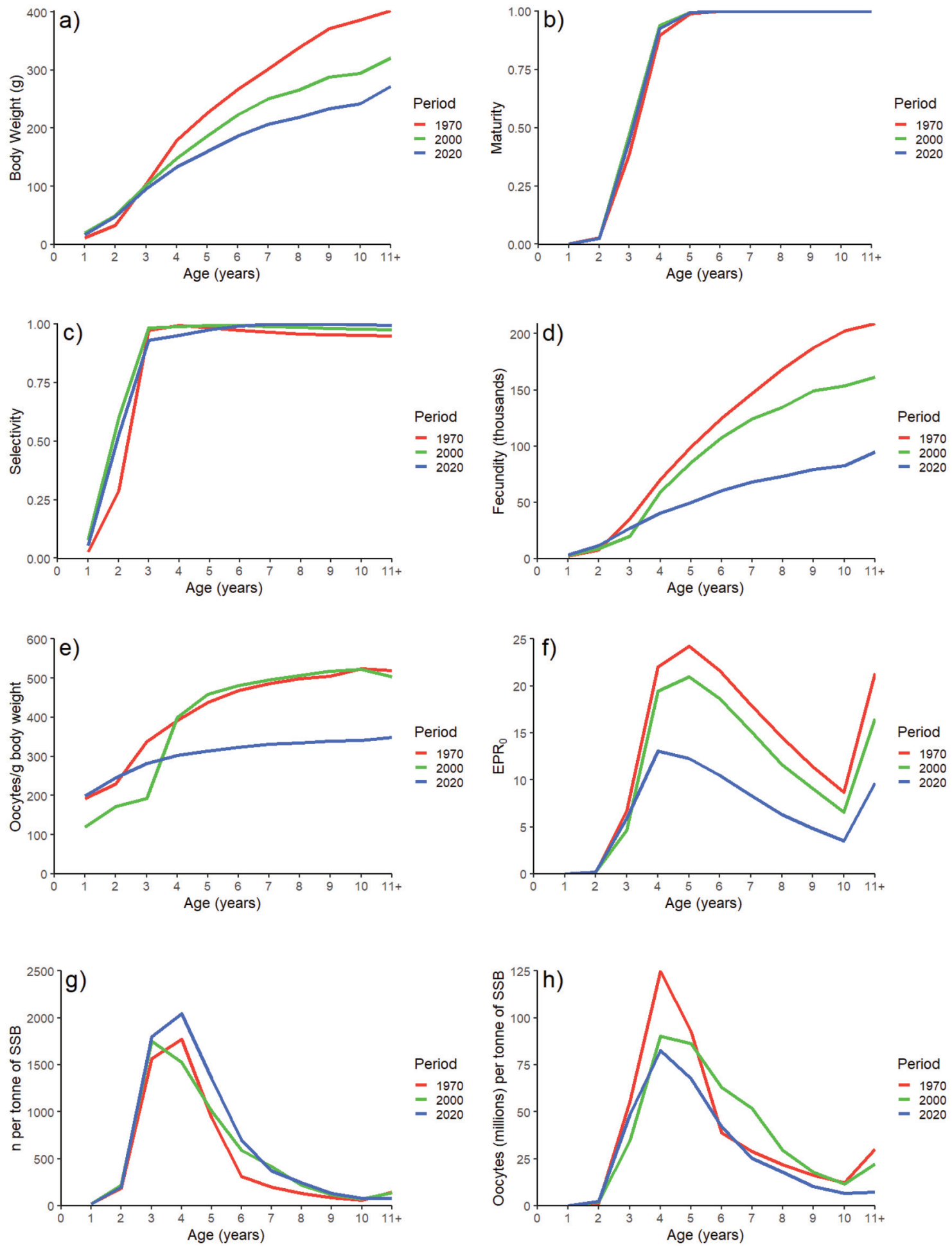

(April-May) spawners in the Gulf of St. Lawrence. Spring spawning Atlantic herring likely undergo oocyte development in the winter, which may impose constraints on fecundity and may explain the apparent change in ranks of the relative fecundity between Scots Bay and German Bank for the present study relative to the early 1970 s.

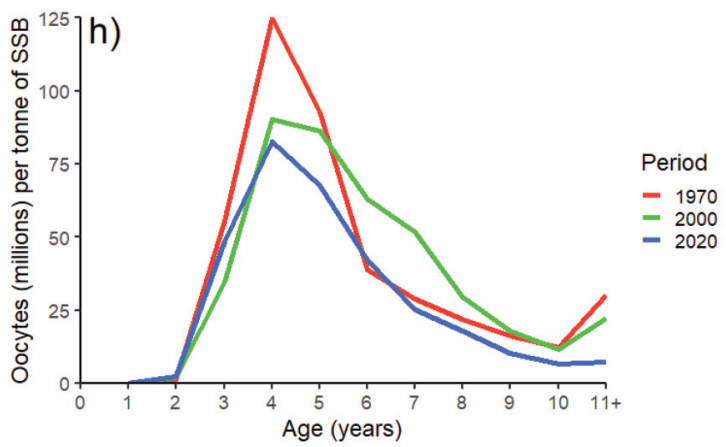

The largest differences in fecundity among spawning grounds in the present study were between Eastern Shore - South Shore and Scots Bay, which are spatially the furthest apart. These differences could be related to egg size, food availability-condition, or gear selectivity. However, further study is needed to understand the mechanisms influencing the spatial differences in fecundity 
Fig. 6. Fecundity-at-age by period $(1970,2000,2020)$ and estimated fecundity-at-age based on time period relative fecundity (oocytes per $g$ body weight) and temporal changes in weight-at-age. For example, " $1970 \Delta$ wt 20 " fecundity is estimated using 1970 oocytes per g body weight and weight-at-age from the 2020 period.

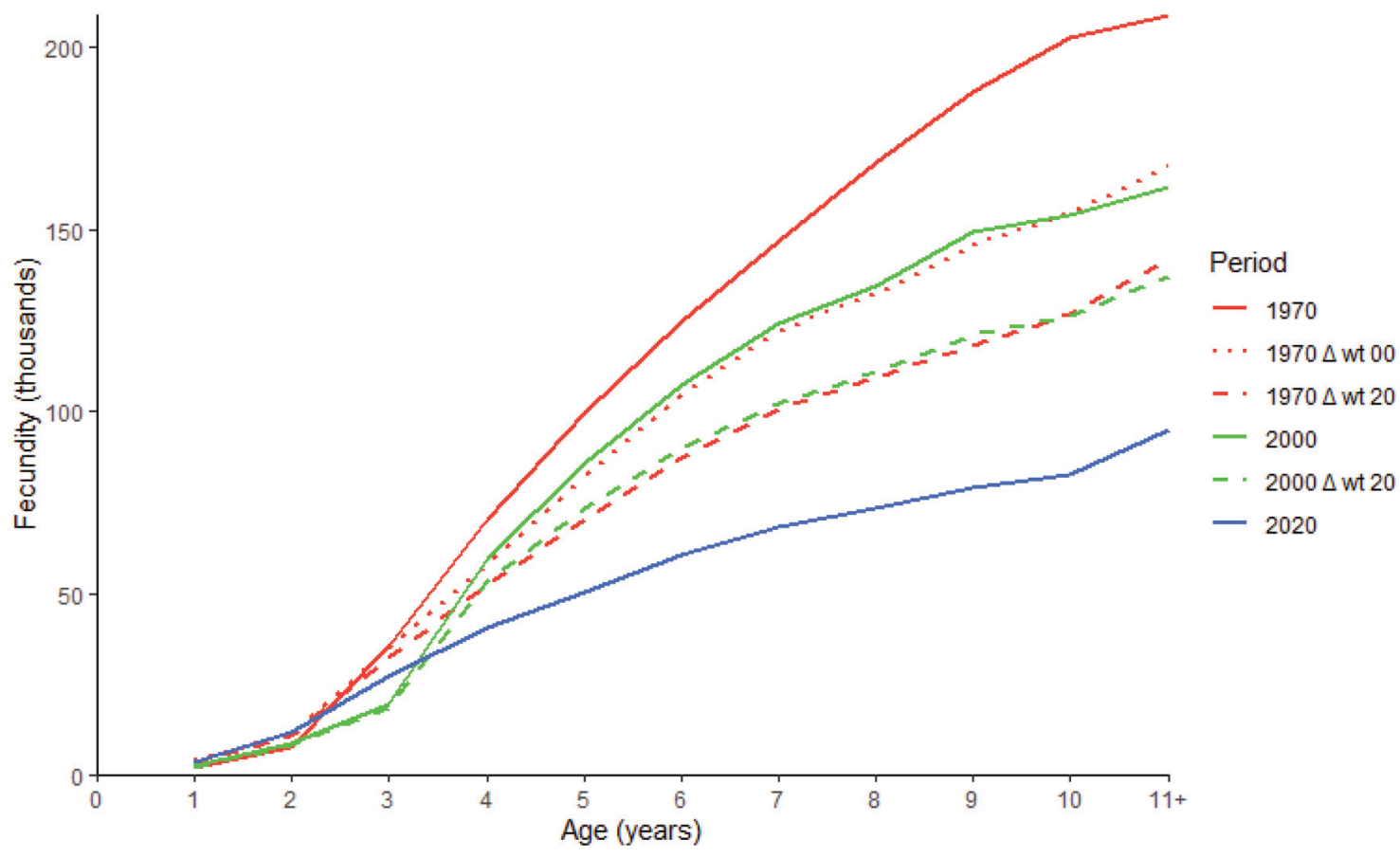

Table 2. Estimates of $S_{S B P R}$ and $\mathrm{EPR}_{0}$ and associated estimates of $F_{M S Y}, M S Y, S_{\text {MSY, }}$, and 2018 stock status based on SSBPR and EPR estimated using biological data (weight-at-age or fecundity-at-age and maturity-at-age) and selectivity-at-age estimated from each time period.

\begin{tabular}{|c|c|c|c|c|c|c|c|c|c|c|}
\hline \multirow[b]{2}{*}{ Period } & \multicolumn{5}{|l|}{ SSBPR } & \multicolumn{5}{|l|}{ EPR } \\
\hline & $\mathrm{SSBPR}_{0}(\mathrm{~g})$ & $F_{\mathrm{MSY}}$ & MSY (kt) & $\mathrm{SSB}_{\mathrm{MSY}}(\mathrm{kt})$ & $\mathrm{SSB}_{2018} / \mathrm{SSB}_{\mathrm{MSY}}$ & $\mathrm{EPR}_{0}\left(\times 10^{3}\right)$ & $F_{\mathrm{MSY}}$ & MSY (kt) & $\mathrm{SSB}_{\mathrm{MSY}}(\mathrm{kt})$ & $\mathrm{SSB}_{2018} / \mathrm{SSB}_{\mathrm{MSY}}$ \\
\hline 1970 & 325 & 0.43 & 115 & 276 & 0.48 & 149 & 0.35 & 113 & 338 & 0.39 \\
\hline 2000 & 275 & 0.39 & 97.3 & 228 & 0.58 & 123 & 0.27 & 93.2 & 326 & 0.40 \\
\hline
\end{tabular}

in the Nova Scotia region. The Eastern Shore - South Shore samples were collected by gill net (Scots Bay, German Bank, and Seal Island by purse seine) due to the nature of the fishery in those areas and the influence of gear selectivity on fecundity is unknown. There are no data to determine whether Atlantic herring from the SWNS-BoF management area share feeding grounds with the Eastern Shore - South Shore management areas. Stock-specific density dependence has been shown in Atlantic herring in the Gulf of Maine (Kelly and Stevenson 1985), but this could not be evaluated for these spawning areas due to a lack of an index of abundance for Eastern Shore or South Shore.

While down-regulation of fecundity by atresia prior to spawning can reduce potential fecundity estimates, Óskarsson and Taggart (2006) showed that atresia had no meaningful effect on fecundity if estimated near spawning time. Herring spawn in schooling "waves" and a school disperses quickly after spawning to make way for a new wave to arrive on the spawning grounds (Stephenson et al. 2009). The residency time on the spawning grounds is believed to be variable but a study by Melvin et al. (2014) estimated residency time on the spawning ground for a wave of herring for German Bank and Scots Bay to be on average approximately 14 days. The influence of atresia and down-regulation of fecundity is not expected to be significant in the present study, given the proximity of sampling to the spawning time and the fact that fecundity estimates were only based on herring with macroscopic maturity stages that correspond to oocytes in a late stage of development.

The magnitude of the slope of the relationship between $\log _{10}$ (Fecundity) and $\log _{10}$ (Body weight) was significantly greater than 1 for all spawning grounds in the present study, consistent with a recent meta-analysis that showed fecundity increases disproportionally to biomass in most exploited fish stocks (Marshall et al. 2021). When fecundity is hyperallometric, the TEP of a population comprised of small-sized fish is much lower compared to the same biomass made up of larger-sized fish (Marshall et al. 2021). This was demonstrated in the present study where the large decreases in weight-at-age observed since 1970 have resulted in an increase in the number of individuals per tonne of SSB. However, despite more individuals per tonne of SSB, the egg production per tonne of SSB in 2020 is $27 \%$ lower than in 1970 . The effect on herring recruitment could be much more significant if eggs and larvae from the larger females have greater survival (Murawski et al. 2001; Beldade et al. 2012; Hixon et al. 2014); however, there is currently insufficient data on egg survival for the larger and more fecund females, and subsequently this additional loss cannot be quantified. There is a trade-off between fecundity and egg size for Atlantic herring (dos Santos Schmidt et al. 2021) so it is possible the lower fecundity is countered by larger egg size. Data on egg size in the region and studies on the influence of egg size on survivability of eggs and larvae specifically in Atlantic herring 
would be needed to understand the implications for herring recruitment.

The 29\% decrease in $\mathrm{SSBPR}_{0}$ and $50 \%$ decrease in $\mathrm{EPR}_{0}$ from 1970 to 2020 observed in the present study also show that SSB is not proportional to TEP. Using SSBPR and ignoring the fecundityat-age data results in an overestimate of $F_{\mathrm{MSY}}$, underestimate of $\mathrm{SSB}_{\mathrm{MSY}}$, and overestimate of stock status that may cause challenges for management. From a conservation perspective, it seems counterintuitive that biomass reference points decrease with decreases in weight-at-age and fecundity-at-age. However, although SSB $_{\mathrm{MSY}}$ is now considerably lower than it was in the past, $F_{\text {MSY }}$ remains relatively stable, which means that MSY has decreased by the same rate as $\operatorname{SSB}_{\mathrm{MSY}}$ (Table 2). In other words, while the stock appears to be in a better state relative to $\operatorname{SSB}_{\mathrm{MSY}}$ in 2020, the MSY for the current period is also lower than it was in the past and future catches will need to be lower than the historical MSY to maintain the stock at or above $\mathrm{SSB}_{\mathrm{MSY}}$.

The implications of reproductive hyperallometry and the observed temporal changes in fecundity in Atlantic herring depends on the management objectives. If the management objective is to maintain the historical reproductive potential, then SSB must be maintained at a higher level than SSB in 1970 to maintain TEP. If the management objective is to achieve MSY in the current productivity regime (last 5 years) then $\mathrm{SSB}_{\mathrm{MSY}}$ will be lower than estimates from 1970 . This disparity may be challenging for management and demonstrates the importance of defining clear management objectives.

Various methods of estimating MSY based BPRs have been suggested when biological parameters are time-varying. These include static equilibrium BRPs using various time frames such as the mean over entire historical time series (Haltuch and Punt 2011), mean over last 10 years (ICES 2021), mean over the last $20-25$ years (Punt et al. 2014), mean over a recent set of years since a regime shift (e.g., sequential $t$ test analysis of regime shift approach; Rodionov 2004), or dynamic BRPs defined as moving averages (e.g., O'Leary et al. 2020) or fully dynamic BRPs that estimate a dynamic unfished SSB based on a projection of SSB over the historical times series with no fishing (e.g., MacCall et al. 1985; Berger 2019). The operational guidance for dealing with changes in productivity also varies among jurisdictions. The guidance in Canada (DFO 2009) is to use as long a time series as possible to capture variability in productivity. In contrast, the ICES (2021) guidance is that biological data from the last 10 years should be used, and a shorter period of 3 or 5 years can be used if there is no evidence of temporal trends. The United States specifies that MSY should be re-estimated as required by changes in the long-term environmental or ecological conditions as part of the Magnuson-Stevens Fishery Conservation and Management Act (eCFR 2021). Given that static (equilibrium) MSY BRPs assume that the system is at equilibrium, the time period selected for biological parameters (i.e., growth, fecundity, maturity, selectivity, natural mortality) can average over random annual variability in these parameters, but directional temporal trends in these parameters would violate the assumptions of equilibrium, implying an alternative method is needed to calculate the BRPs. On the other hand, a fully dynamic BRP assumes that temporal changes in the biological parameters are not related to fishing pressure and are not densitydependent (Berger 2019), which requires either further data evaluation or specific assumptions pertaining to the causes of the changes in biological parameters to be made.

The temporal changes in biological parameters (i.e., growth and fecundity) in the present study had a large impact on $\mathrm{SSB}_{\mathrm{MSY}}$ and estimated stock status. The objective of the comparisons in the present study was not to select an appropriate time series for defining BRPs for the SWNS-BoF Atlantic herring management unit, but to evaluate the influence of the temporal changes in biological parameters on BRPs. The $29 \%$ decrease in $\mathrm{SSB}_{\mathrm{MSY}}$ from 1970 to 2020 has a large implication for fishery management and fishery objectives need to be clearly framed. As discussed above, the management objective could be to maintain a level of SSB or
TEP from a historical time period. Alternatively, the management objective could be to accept that the changes in biological parameters have occurred and manage the fishery sustainably (in terms of MSY reference points) at a lower SSB level.

These two views can be countered by various arguments. Historical conditions (e.g., weight-at-age in 1970) may no longer be attainable given the observed change in biological parameters over time. Many fish stocks have observed decreases in weight-atage since the 1960s (Charbonneau et al. 2019), and a reversal of declines in weight-at-age may not necessarily occur with an increase in stock abundance. For example, weight-at-age continued to decrease during a period of stock recovery for North Sea herring due to density dependence (Dickey-Collas et al. 2010), and while age-structure may recover with increases in biomass, weight-at-age may not recover (Charbonneau et al. 2019). Determining the mechanisms for changes in biological parameters may prove difficult. Various factors such as changes in climate (e.g., Pinsky and Mantua 2014; Szuwalski and Hollowed 2016), food availability (e.g., Brosset et al. 2019), fishing selectivity (e.g., Law 2000), and density dependence (e.g., Lorenzen and Enberg 2002; Wang et al. 2021) may contribute to these changes. A recent study of growth in Atlantic herring in the Gulf of Maine found that density dependence was the primary driver of temporal changes in growth compared to sea surface temperature and salinity (Becker et al. 2020). Many stocks have taken one-way trips and the collinearity between time and environmental parameters such as temperature (e.g., Turner 2017) preclude the identification of causal factors. Further study would be needed to understand the causes of changes in biological parameters in Atlantic herring (and fish stocks in general), and if the relative contributions of changes due to fishing pressure can be separated from other factors, this could be used in BRP calculations.

The results from this study have demonstrated the importance of considering changes in the biological parameters (growth and fecundity) in the estimation of BRPs. If the SWNS-BoF Atlantic herring management unit continues to be managed based on SSB and an empirical limit reference point approximating that indicator, the implications of the composition and therefore the reproductive value of a tonne of SSB (more individuals per tonne but overall lower TEP), should be considered. Statistically significant differences in fecundity-at-size between 2019 and 2020 and between the two primary spawning grounds (German Bank and Scots Bay) of the SWNS-BoF management unit suggest that annual monitoring of fecundity at each spawning ground may be needed to reliably estimate $\mathrm{EPR}_{0}$. The relative stability of the $\mathrm{F}_{\mathrm{MSY}}$ reference points over time when biological parameters are changing suggests management based on $F$ reference points may be preferred over management based on the equilibrium $S_{S B} B_{M S Y}$ reference points that are sensitive to changes in those biological parameters. Careful consideration of fishery objectives is needed by resource managers, fishery scientists, and stakeholders in the selection of BRPs and the reference time period used for characterizing biological parameters in the estimation of BRPs.

\section{Competing interests statement}

The authors declare there are no competing interests.

\section{Funding statement}

This research was funded by Fisheries and Oceans Canada.

\section{Data availability statement}

The data for this project are published on the Government of Canada's Open Data Platform: https://open.canada.ca/data/en/ dataset/e39b1318-c9f7-4686-b5e5-7d838c8ac99a. 


\section{Acknowledgements}

The authors are grateful for field and laboratory support from Carissa Grove, Lisa Houston, Derek Knox, Art MacIntyre, and Quinn McCurdy and sample collection and logistical support from Janette Faulkner, Trevor Lord, and Billy Saulnier. The authors also thank Julie Marentette, Yanjun Wang, and two anonymous reviewers for providing comments that greatly improved this manuscript.

\section{References}

Barneche, D.R., Robertson, D.R., White, C.R., and Marshall, D.J. 2018. Fish reproductive-energy output increases disproportionately with body size. Science, 360(6389): 642-645. doi:10.1126/science.aao6868. PMID:29748282.

Becker, J.R., Cieri, M.D., Libby, D.A., St. Gelais, A., Sherwood, G., and Chen, Y. 2020. Temporal variability in size and growth of Atlantic herring in the Gulf of Maine. J. Fish Biol. 97(4): 953-963. doi:10.1111/jfb.14430. PMID:32529667.

Beldade, R., Holbrook, S.J., Schmitt, R.J., Planes, S., Malone, D., and Bernardi, G. 2012. Larger female fish contribute disproportionately more to self-replenishment. Proc. Biol. Sci. 279: 2116-2121. doi:10.1098/rspb.2011.2433. PMID:22279163.

Berger, A.M. 2019. Character of temporal variability in stock productivity influences the utility of dynamic reference points. Fish. Res. 217: 185-197. doi:10.1016/j.fishres.2018.11.028.

Bradford, R.G., and Stephenson, R.L. 1992. Egg weight, fecundity, and gonad weight variability among northwest Atlantic herring (Clupea harerigus) populations. Can. J. Fish. Aquat. Sci. 49(10): 2045-2054. doi:10.1139/192-227.

Brooks, E.N., Powers, J.E., and Cortés, E. 2010. Analytical reference points for age-structured models: application to data-poor fisheries. ICES J. Mar. Sci. 67(1): 165-175. doi:10.1093/icesjms/fsp225.

Brosset, P., Doniol-Valcroze, T., Swain, D.P., Lehoux, C., Van Beveren, E., Mbaye, B.C., et al. 2019. Environmental variability controls recruitment but with different drivers among spawning components in Gulf of St. Lawrence herring stocks. Fish. Oceanogr. 28: 1-17. doi:10.1111/fog.12272.

Brown Peterson, N.J., Wyanski, D.M., Saborido-Rey, F., Macewicz, B.J., and Lowerre-Barbieri, S.K. 2011. A standardized terminology for describing reproductive development in fishes. Mar. Coast. Fish. 3: 52-70. doi:10.1080/ 19425120.2011.555724.

Charbonneau, J.A., Keith, D.M., and Hutchings, J.A. 2019. Trends in the size and age structure of marine fishes. ICES J. Mar. Sci. 76(4): 938-945. doi:10.1093/icesjms/fsy180.

DFO. 2009. A fishery decision-making approach incorporating the precautionary approach. Fisheries and Oceans Canada. Available from https:/| www.dfo-mpo.gc.ca/reports-rapports/regs/sff-cpd/precaution-eng.htm [Accessed 13 August 2021]

DFO. 2020. Science Response 2020/050: stock status update of 4VWX herring for the 2019/2020 fishing season. Canadian Science Advisory Secretariat, Ottawa, Ont.

Dickey-Collas, M., Nash, R.D.M., Brunel, T., van Damme, C.J.G., Marshall, C.T., Payne, M.R., et al. 2010. Lessons learned from stock collapse and recovery of North Sea herring: a review. ICES J. Mar. Sci. 67(9): 1875-1886. doi:10.1093/ icesjms/fsq033.

dos Santos Schmidt, T.C., Slotte, A., Kennedy, J., Sundby, S., Johannessen, A., Óskarsson, G.J., et al. 2017. Oogenesis and reproductive investment of Atlantic herring are functions of not only present but long-ago environmental influences as well. Proc. Natl. Acad. Sci. U.S.A. 114(10): 2634-2639. doi:10.1073/ pnas.1700349114. PMID:28223491.

dos Santos Schmidt, T.C., Hay, D.E., Sundby, S., Devine, J.A., Óskarsson, G.J., Slotte, A., et al. 2021. Adult body growth and reproductive investment vary markedly within and across Atlantic and Pacific herring: a metaanalysis and review of 26 stocks. Rev. Fish Biol. Fish. 31: 685-708. doi:10.1007/s11160-021-09665-9.

eCFR. 2021. Title 50: Wildlife and Fisheries, Part 600: Magnuson-Stevens Act Provisions, Subpart D: National Standards. Electronic Code of Federal Regulations. Available from https://www.ecfr.gov/cgi-bin/text-idx?SID= 71b8c6026001cb90e4b0925328dce685\&mc=true\&node=se50.12.600_1310\&rgn= div8 [Accessed 13 August 2021].

Haltuch, M.A., and Punt, A.E. 2011. The promises and pitfalls of including decadal-scale climate forcing of recruitment in groundfish stock assessment. Can. J. Fish. Aquat. Sci. 68(5): 912-926. doi:10.1139/f2011-030.

Hixon, M.A., Johnson, D.W., and Sogard, S.M. 2014. BOFFFFs: on the importance of conserving old-growth age structure in fishery populations. ICES J. Mar. Sci. 71(8): 2171-2185. doi:10.1093/icesjms/fst200.

Hunter, J.R., Lo, N.C.H., and Leong, R.J.H. 1985. Batch fecundity in multiple spawning fishes. An egg production method for estimating spawning biomass of pelagic fish: application to the northern anchovy, Engraulis mordax. Edited by R. Lasker. NOAA Technical Report NMFS 36. US Department of Commerce, National Oceanic and Atmospheric Administration, National Marine Fisheries Service. pp. 67-78.

ICES. 2021. ICES fisheries management reference points for category 1 and 2 stocks. ICES technical guidelines. Available from https://www.ices.dk/sites/ pub/Publication\%20Reports/Guidelines\%20and\%20Policies/16.04.03.01_Reference points_for_category_1_and_2.pdf [Accessed 13 August 2021].
Kell, L.T., Nash, R.D., Dickey-Collas, M., Mosqueira, I., and Szuwalski, C. 2016. Is spawning stock biomass a robust proxy for reproductive potential? Fish Fish. 17(3): 596-616, doi:10.1111/faf.12131.

Kelly, K.H., and Stevenson, D.K. 1985. Fecundity of Atlantic herring (Clupea harengus) from three spawning areas in the western Gulf of Maine, 1969 and 1982. J. Northw. Atl. Fish. Sci. 6: 149-155. doi:10.2960/J.v6.a15.

Kelso, N.V., 2021. Shapefile: ne_10m_coastline.shp. Available from https:/ github.com/nvkelso/natural-earth-vector/tree/master/10m_physical [Accessed 22 December 2021].

Kjesbu, O.S. 2009. Applied fisheries reproductive biology: contribution of individual reproductive potential to recruitment and fisheries management. In Fish Reproductive Biology and its Implications for Assessment and Management. Edited by T. Jakobsen, M. Fogarty, B.A. Megrey, and E. Moksness. Blackwell Science Ltd., Oxford, UK. pp. 321.

Kurita, Y., and Kjesbu, O.S. 2009. Fecundity estimation by oocyte packing density formulae in determinate and indeterminate spawners: theoretical considerations and applications. J. Sea Res. 61(3): 188-196. doi:10.1016/ j.seares.2008.10.010.

Kurita, Y., Meier, S., and Kjesbu, O.S. 2003. Oocyte growth and fecundity regulation by atresia of Atlantic herring (Clupea harengus) in relation to body condition throughout the maturation cycle. J. Sea. Res. 49(3): 203219. doi:10.1016/S1385-1101(03)00004-2.

Landry, J., and McQuinn, I.H. 1988. Guide to microscopic and macroscopic identification of the sexual maturity stages of the Atlantic herring (Clupea harengus harengus L.). Can. Tech. Rep. Fish. Aquat. Sci. 1655.

Law, R.L. 2000. Fishing, selection, and phenotypic evolution. ICES J. Mar. Sci. 57(3): 659-668. doi:10.1006/jmsc.2000.0731.

Lenth, R.V., Buerkner, P., Herve, M., Love, J., Riebl, H., and Singmann, H., 2021. Package 'emmeans': estimated marginal means, aka least-squares means. Version 1.6.2-1. Available from https://cran.r-project.org/web/packages/ emmeans/emmeans.pdf [Accessed 13 August 2021].

Lorenzen, K., and Enberg, K. 2002. Density-dependent growth as a key mechanism in the regulation of fish populations: evidence from among-population comparisons. Proc. Biol. Sci. 269: 49-54. doi:10.1098/rspb.2001.1853. PMID:11788036.

MacCall, A.D., Klingbeil, R.A., and Methot, R.D. 1985. Recent increased abundance and potential productivity of Pacific mackerel (Scomber japonicus). CalCOFI Rep. Vol. 26. La Jolla, Calif. 119-129.

Mangel, M., MacCall, A.D., Brodziak, J., Dick, E.J., Forrest, R.E., Pourzand, R., and Ralston, S. 2013. A perspective on steepness, reference points, and stock assessment. Can. J. Fish. Aquat. Sci. 70(6): 930-940. doi:10.1139/cjfas2012-0372.

Marshall, C.T., Yaragina, N.A., Lambert, Y., and Kjesbu, O.S. 1999. Total lipid energy as a proxy for total egg production by fish stocks. Nature, 402: 288-290. doi:10.1038/46272.

Marshall, D.J., Bode, M., Mangel, M., Arlinghaus, R., and Dick, E.J. 2021. Reproductive hyperallometry and managing the world's fisheries. Proc. Natl. Acad. Sci. U.S.A. 118(34): e2100695118. doi:10.1073/pnas.2100695118. PMID:34400498.

Melvin, G.D., Stephenson, R.L., and Power, M.J. 2009. Oscillating reproductive strategies of herring in the western Atlantic in response to changing environmental conditions. ICES J. Mar. Sci. 66(8): 1784-1792. doi:10.1093/ icesjms/fsp173.

Melvin, G.D., Power, M.J., and Knox, D., 2010. Herring ageing: re-ageing of Atlantic herring otoliths and the development of a revised catch at age. Canadian Science Advisory Secretariat Research Document 2010/101. Fisheries and Oceans Canada, Ottawa, Ont. Available from https://wavesvagues.dfo-mpo.gc.ca/Library/342312.pdf.

Melvin, G.D., Martin, R., and Power, M.J. 2014. Estimating German Bank and Scots Bay herring spawning ground turnover rates from tag returns. Research Document 2014/068. Fisheries and Oceans Canada, Ottawa, Ont.

Messieh, S.N. 1976. Fecundity studies on Atlantic herring from the southern Gulf of St. Lawrence and along the Nova Scotia Coast. Trans. Am. Fish. Soc. 3: 384-394. doi:10.1577/1548-8659(1976)105<384:FSOAHF $>2.0$.CO;2.

Miller, T.J., and Brooks, E.N. 2021. Steepness is a slippery slope. Fish Fish. 22(3): 634-645. doi:10.1111/faf.12534.

Murawski, S.A., Rago, P.J., and Trippel, E.A. 2001. Impacts of demographic variation in spawning characteristics on reference points for fishery management. ICES J. Mar. Sci. 58(5): 1002-1014. doi:10.1006/jmsc.2001.1097.

Myers, R.A., Rosenberg, A.A., Mace, P.M., Barrowman, N., and Restrepo, V.R. 1994. In search of thresholds for recruitment overfishing. ICES J. Mar. Sci. 51(2): 191-205. doi:10.1006/jmsc.1994.1020.

Nakatsuka, S., Ishida, Y., Fukuda, H., and Akita, T. 2017. A limit reference point to prevent recruitment overfishing of Pacific Bluefin tuna. Mar. Policy, 78: 107-113. doi:10.1016/j.marpol.2017.01.017.

O'Leary, C.A., Thorson, J.T., Miller, T.J., and Nye, J.A. 2020. Comparison of multiple approaches to calculate time-varying biological reference points in climate-linked population-dynamics models. ICES J. Mar. Sci. 77(3): 930-941. doi:10.1093/icesjms/fsz215.

Óskarsson, G.J., and Taggart, C.T. 2006. Fecundity variation in Icelandic summer-spawning herring and implications for reproductive potential. ICES J. Mar. Sci. 63(3): 493-503. doi:10.1016/j.icesjms.2005.10.002.

Óskarsson, G.J., Kjesbu, O.S., and Slotte, A. 2002. Predictions of realised fecundity and spawning time in Norwegian spring-spawning herring (Clupea harengus). J. Sea Res. 48(1): 59-79. doi:10.1016/S1385-1101(02)00135-1. 
Óskarsson, G.J., Taggart, C.T., and Stephenson, R.L. 2016. Fecundity and reproductive potential of Scotia-Fundy summer- and autumn-spawning herring. (Clupea harengus L.). Can. Tech. Rep. Fish. Aquat. Sci. 3182.

Perkins, F.E., and Anthony, V.C. 1969. A note of the fecundity of herring (Clupea harengus L.) from Georges Bank, the Gulf of Maine and Nova Scotia. ICNAF Redbook 1969, part 3. pp. 33-38.

Pinsky, M.L., and Mantua, N.J. 2014. Emerging adaptation approaches for climate ready fisheries management. Oceanography, 27(4): 146-159. doi:10.5670/ oceanog.2014.93.

Punt, A.E., A'mar, T., Bond, N.A., Butterworth, D.S., de Moor, C.L., De Oliveira, J.A.A. et al. 2014. Fisheries management under climate and environmental uncertainty: control rules and performance simulation. ICES J. Mar. Sci. 71(8): 2208-2220. doi:10.1093/icesjms/fst057.

R Core Team. 2020. R: a language and environment for statistical computing. R Foundation for Statistical Computing, Vienna, Austria. Available from https://www.R-project.org/.

Rideout, R.M., and Morgan, M.J. 2007. Major changes in fecundity and the effect on population egg production for three species of north-west Atlantic flatfishes. J. Fish Biol. 70(6): 1759-1779. doi:10.1111/j.1095-8649.2007.01448.x.

Rijnsdorp, A.D., van Damme, C.J.G., and Witthames, P.R. 2010. Implications of fisheries-induced changes in stock structure and reproductive potential for stock recovery of a sex-dimorphic species, North Sea plaice. ICES J. Mar. Sci. 67(9): 1931-1938. doi:10.1093/icesjms/fsq049.

Singh, R, Knox, D., and MacIntyre, A, 2020. 2019 Southwest Nova Scotia/Bay of Fundy Atlantic herring framework: data inputs. Canadian Science Advisory Secretariat Research Document 2020/028. Fisheries and Oceans Canada, Ottawa, Ont. Available from https://waves-vagues.dfo-mpo.gc.ca/Library/40946265.pdf.

Rodionov, S.N. 2004. A sequential algorithm for testing climate regime shifts. Geophys. Res. Lett. 31(9): L09204. doi:10.1029/2004GL019448.

Rogers, R., Rowe, S., Rideout, R.M., and Morgan, M.J. 2019. Fecundity of haddock (Melanogrammus aeglefinus) off southern Newfoundland. Fish. Res. 220: 105339. doi:10.1016/j.fishres.2019.105339.
Shelton, P.A., and Rice, J.C. 2002. Limits to overfishing: reference points in the context of the Canadian perspective on the precautionary approach. Canadian Science Advisory Secretariat Research Document 2020/084. Fisheries and Oceans Canada, Ottawa, Ont

Stephenson, R.L., Melvin, G.D., and Power, M.J. 2009. Population integrity and connectivity in Northwest Atlantic herring: a review of assumptions and evidence. ICES J. Mar. Sci. 66(8): 1733-1739. doi:10.1093/icesjms/fsp189.

Szuwalski, C.S., and Hollowed, A.B. 2016. Climate change and non-stationary population processes in fisheries management. ICES J. Mar. Sci. 73(5): 1297-1305. doi:10.1093/icesjms/fsv229.

Trippel, E.A. 1998. Egg size and viability and seasonal offspring production of young Atlantic cod. Tran. Am. Fish. Soc. 127(3): 339-359. doi:10.1577| 1548-8659(1998)127<0339:ESAVAS $>2.0$. CO;2.

Turner, R.E. 2017. Smaller size-at-age menhaden with coastal warming and fishing intensity. Geo Geogr. Environ. 4(2): e00044. doi:10.1002/geo2.44.

van Damme, C.J.G., Dickey-Collas, M., Rijnsdorp, A.D., and Kjesbu, O.S. 2009. Fecundity, atresia, and spawning strategies of Atlantic herring (Clupea harengus). Can. J. Fish. Aquat. Sci. 66(12): 2130-2141. doi:10.1139/F09-153.

Walters, C.J., and Martel, S.J.D. 2004. Fisheries ecology and management. Princeton University Press, Oxford, UK.

Wang, Y., Gharouni, A., Friedland, K.D., and Melrose, D.C. 2021. Effect of environmental factors and density-dependence on somatic growth of Eastern Georges Bank haddock (Melanogrammus aeglefinus). Fish. Res. 240: 105954. doi:10.1016/j.fishres.2021.105954.

Wuenschel, M.J., and Deroba, J.J. 2019. The reproductive biology of female Atlantic herring in U.S. waters: validating classification schemes for assessing the importance of spring and skipped spawning. Mar. Coast. Fish. 11(6): 487-505. doi:10.1002/mcf2.10099.

Zhou, S., Punt, A.E., Lei, Y., Deng, R.A., and Hoyle, S.D. 2020. Identifying spawner biomass per-recruit reference points from life-history parameters. Fish Fish. 21(4): 760-773. doi:10.1111/faf.12459. 